\title{
Primary Laparoscopic Surgery Does Not Affect the Prognosis of Early-Stage Ovarian Clear Cell Cancer
}

\author{
Sheng Yin $\mathbb{1 D}^{1, *}$ \\ Wen $\mathrm{Gao}^{2, *}$ \\ Peipei Shi' \\ Meili $\mathrm{Xi}^{1}$ \\ Wenbin Tang' \\ Jiarong Zhang'
}

'Department of Obstetrics and Gynecology, Zhongshan Hospital, Fudan University, Shanghai, 200032, People's Republic of China; ${ }^{2}$ Department of Gynaecologic Oncology, The Cancer Hospital of the University of Chinese Academy of Sciences (Zhejiang Cancer Hospital), Institute of Basic Medicine and Cancer (IBMC), Chinese Academy of Sciences, Hangzhou, Zhejiang, 310022, People's Republic of China

*These authors contributed equally to this work
Correspondence: Jiarong Zhang Department of Obstetrics and Gynecology, Zhongshan Hospital, Fudan University, Fenglin Road, I80\#, Xuhui District, Shanghai, 200032, People's

Republic of China

Tel +86 2I-6404I990

Email zhang.jiarong@zs-hospital.sh.cn
Purpose: Minimally invasive surgery (MIS) is performed frequently in early-stage ovarian cancer patients, especially in ovarian clear cell carcinoma (OCCC). The aim of this study was to investigate whether primary laparoscopic surgery influences prognosis in patients with early-stage OCCC.

Patients and Methods: Patients with International Federation of Gynecology and Obstetrics (FIGO) stage I OCCC were retrospectively reviewed in two hospitals between April 2010 and August 2020. Clinical data were abstracted, and patients were followed up until February 2021. Patients were divided into open surgery (laparotomy) and laparoscopy groups, and the Kaplan-Meier method was applied to compare progression-free survival (PFS) and overall survival (OS) between the groups. Statistical differences were determined by the Log rank test.

Results: Eighty-nine patients were included in the study; $20(22.5 \%)$ and $69(77.5 \%)$ patients underwent laparoscopic and open surgery, respectively. The patients' characteristics were well-balanced except that patients in the laparoscopy group tended to have smaller tumors and lower frequency of omentectomy and lymphadenectomy compared with the open surgery group. The median follow-up duration was 42.6 and 36.5 months in the laparoscopy and open surgery groups, respectively. Nine (10.1\%) patients developed recurrence, and 4 $(4.5 \%)$ died of the disease; all in the open surgery group. The estimated 2-year PFS rates were $100.0 \%$ and $90.1 \%$, and the estimated 5 -year OS rates were $100.0 \%$ and $91.9 \%$ in the laparoscopy and open surgery groups, respectively. No significant survival differences were found between the groups.

Conclusion: Survival was not compromised when primary laparoscopic surgery was performed in early-stage OCCC patients. A well-designed randomized controlled trial is warranted.

Keywords: laparoscopic surgery, early-stage ovarian clear cell cancer, prognosis

\section{Introduction}

Epithelial ovarian cancer (EOC) is the most lethal gynecologic malignancy and ranks fifth in cancer deaths among women. ${ }^{1}$ Ovarian clear cell cancer (OCCC), a subtype accounting for approximately 5-25\% of all EOCs, is always diagnosed at an early stage and is confined to the ovary as a pelvic mass. Previous studies have shown that OCCC is relatively less aggressive in the early stage ${ }^{2}$ but may develop chemo-resistance in the advanced stage, leading to a significantly poorer prognosis compared with high-grade serous ovarian cancer., 3 
With developments in minimally invasive techniques, especially the wide use of laparoscopy, more gynecologic oncologists are considering minimally invasive surgery (MIS) in select patients. ${ }^{5}$ MIS was first applied to assess tumor burden and to evaluate the resectability of advancedstage ovarian cancer. ${ }^{6}$ Recent studies have investigated the feasibility of MIS for interval debulking surgery after neoadjuvant chemotherapy ${ }^{7,8}$ and for secondary cytoreductive surgery in appropriate recurrent ovarian cancer patients. ${ }^{9-12}$ Additionally, for patients with apparent early-stage ovarian cancer, MIS has been applied for full staging surgery. ${ }^{13-16}$ However, as the LACC trial suggested that MIS was associated with lower progression-free survival (PFS) and overall survival (OS) compared with laparotomy in early-stage cervical cancer, ${ }^{17}$ gynecological oncologists began to pay attention to patients' survival, which may be affected by MIS, especially in ovarian cancers. Furthermore, as OCCC is associated with endometriosis and because most OCCC patients are diagnosed in the early stage, MIS appears to be applied more frequently in this subtype of ovarian cancer.

Herein, we conducted a retrospective study involving consecutive International Federation of Gynecology and Obstetrics (FIGO) stage I OCCC patients. Each patient's clinical characteristics, treatment, and prognosis data were carefully collected and analyzed. Specifically, we divided the patients into two groups, namely a laparoscopy group and an open surgery group, according to whether primary laparoscopic surgery was performed. We aimed to investigate whether MIS impacts the survival of patients with FIGO stage I OCCC, compared with open surgery.

\section{Patients and Methods}

\section{Study Subjects}

This was a two-center, retrospective, cohort study conducted in Fudan University Zhongshan Hospital and Zhejiang Cancer Hospital between April 2010 and August 2020. Data for patients who were pathologically confirmed as having OCCC were reviewed and collected. In this study, only patients diagnosed as FIGO stage I OCCC were included. This study was approved by the medical ethics committees of Fudan University Zhongshan Hospital and Zhejiang Cancer Hospital. The need for written informed consent was waived owing to the retrospective anonymized data collection. The private information of all enrolled patients was carefully protected, and the study was conducted in accordance with the guidelines of the Declaration of Helsinki.

\section{Study Protocol}

Medical records were abstracted to obtain the patients' age at diagnosis, preoperative serum cancer antigen 125 (CA125) value, preoperative CA199 value, FIGO stage, type of surgery (open or laparoscopic), tumor size, tumor location, ascites volume, postoperative adjuvant chemotherapy, chemotherapy cycles, PFS, and OS. Patients were followed up every 3 months for the first 2 years, then every 6 months for the next 3 years, and annually, thereafter. The last follow-up date was February 2021.

\section{Definitions}

In our study, patients were divided into two groups, namely a laparoscopy group and a laparotomy (open surgery) group. The laparoscopy group was defined as undergoing primary laparoscopic surgery, including full laparoscopic staging surgery and conversion to open surgery. The laparotomy group was defined as undergoing open surgery directly. PFS was defined as the time from the primary surgery to the date of recurrence, and OS was calculated as the time from the primary surgery to the date of death.

\section{Statistical Analysis}

The SPSS software package for windows (version 19.0; IBM Corp., Armonk, NY, USA) was used for statistical analysis. Quantitative data were expressed as medians. The Kaplan-Meier method was used to compare survival between the two groups, and the statistical differences were determined by the Log rank test. A $p$-value $<0.05$ was considered statistically significant.

\section{Results}

\section{Baseline and Patients' Characteristics}

Eighty-nine patients diagnosed as FIGO stage I OCCC were included in this study. The median age was 51.0 years (range, 32-75 years); 37 (41.6\%) patients were diagnosed as FIGO stage IA and $56.2 \%$ as stage IC. The median preoperative CA125 and CA199 values were $43.5 \mathrm{U} / \mathrm{mL}$ and $20.3 \mathrm{U} / \mathrm{mL}$, respectively. Most (60.7\%) patients had a tumor size $>80 \mathrm{~mm}$, and $18.0 \%$ had an ascites volume of $>200 \mathrm{~mL}$. Almost all patients (97.8\%) had a unilateral tumor except for two cases. After primary staging surgery, $82(92.1 \%)$ patients received platinumbased chemotherapy, and $74(83.1 \%)$ patients received four or more cycles of chemotherapy, while six (6.7\%) patients did not undergo chemotherapy. 
Overall, 20 (22.4\%) patients underwent primary laparoscopy as the primary staging surgery, and $69(77.6 \%)$ patients underwent open surgery directly. As shown in Table 1, clinical characteristics, namely age at diagnosis, FIGO stage, preoperative CA125 and CA199 values, tumor location, ascites volume, and chemotherapy cycles were wellbalanced between the two groups. Patients with large tumor size $(>8 \mathrm{~cm})$ tended to undergo open surgery $(p=0.003)$.

\section{Surgical Procedures}

Surgical procedures for the entire cohort are summarized in Table 2. Overall, 80 (89.9\%) patients underwent hysterectomy, and $9(10.1 \%)$ patients underwent fertility-preserving surgery. There was no statistically significant difference in the rates of hysterectomy, salpingooophorectomy, peritoneal biopsy, and appendectomy.
Omentectomy $(75.0 \%$ versus $100.0 \% ; p<0.001)$ and lymphadenectomy $(50.0 \%$ versus $81.2 \% ; p=0.009)$ were less frequent in the laparoscopy group versus the open surgery group, respectively. Of the 66 patients receiving lymphadenectomy, $19(28.8 \%)$ and $3(4.5 \%)$ patients underwent only pelvic or para-aortic lymphadenectomy, respectively, and $44(66.7 \%)$ patients underwent systematic lymphadenectomy. Of the 20 patients who underwent laparoscopic surgery, $10(50.0 \%)$ were converted to laparotomy immediately, and 2 (10.0\%) underwent delayed open surgery staging.

\section{Prognosis Between the Laparoscopy and Laparotomy Groups}

As of February 2021, the median follow-up duration for the entire cohort was 40.7 months (range, 6.6-108.9

Table I Clinical Characteristics

\begin{tabular}{|c|c|c|c|c|}
\hline Characteristics & $N=89$ & Laparoscopy $(\mathbf{N}=\mathbf{2 0})$ & Laparotomy $(\mathrm{N}=69)$ & $P$ value \\
\hline Median age (years) & 51.0 & 49.0 & 53.0 & 0.124 \\
\hline \multicolumn{5}{|l|}{ FIGO stage } \\
\hline IA & $37(4 I .6 \%)$ & II (55.0\%) & $26(37.7 \%)$ & \\
\hline IB & $2(2.2 \%)$ & I (5.0\%) & I (I.4\%) & \\
\hline IC & $50(56.2 \%)$ & $8(40.0 \%)$ & $42(60.9 \%)$ & 0.203 \\
\hline Median CAI25 (U/mL) & 43.5 & 25.0 & 63.0 & 0.393 \\
\hline Median CAI99 (U/mL) & 20.3 & 9.9 & 25.2 & 0.232 \\
\hline \multicolumn{5}{|l|}{ Tumor size $(\mathrm{mm})$} \\
\hline$\leq 80$ & $29(32.6 \%)$ & $10(50.0 \%)$ & $19(27.5 \%)$ & \\
\hline$>80$ & $54(60.7 \%)$ & $6(30.0 \%)$ & $48(69.6 \%)$ & \\
\hline NA & $6(6.7 \%)$ & $4(20.0 \%)$ & $2(3.0 \%)$ & 0.003 \\
\hline \multicolumn{5}{|l|}{ Ascites } \\
\hline None & 72 (80.9\%) & $19(95.0 \%)$ & $53(76.8 \%)$ & \\
\hline Yes & $16(18.0 \%)$ & I (5.0\%) & $15(21.7 \%)$ & \\
\hline NA & I (I.I\%) & 0 & I (I.4\%) & 0.106 \\
\hline \multicolumn{5}{|l|}{ Laterality } \\
\hline Unilateral & 87 (97.8\%) & 19 (95.0\%) & $68(98.6 \%)$ & \\
\hline Bilateral & $2(2.2 \%)$ & I (5.0\%) & I (I.4\%) & 0.401 \\
\hline \multicolumn{5}{|l|}{ Chemotherapy } \\
\hline Platinum-based & $82(92.1 \%)$ & $19(95.0 \%)$ & $63(91.3 \%)$ & \\
\hline Others & I (I.I\%) & 0 & $\mathrm{I}(\mathrm{I} .4 \%)$ & \\
\hline No chemo & $6(6.7 \%)$ & I (5.0\%) & $5(7.2 \%)$ & 0.787 \\
\hline \multicolumn{5}{|l|}{ Chemo cycles } \\
\hline 0 & $6(6.7 \%)$ & I (5.0\%) & $5(7.2)$ & \\
\hline $\mathrm{I}-3$ & $9(10.1 \%)$ & $4(20.0 \%)$ & $5(7.2 \%)$ & \\
\hline$\geq 4$ & 74 (83.1\%) & I5 (75.0\%) & 59 (85.5\%) & 0.245 \\
\hline
\end{tabular}

Abbreviations: FIGO, International Federation of Gynecology and Obstetrics; NA, not acquired. 
Table 2 Surgical Procedures

\begin{tabular}{|c|c|c|c|c|}
\hline Variable & $N=89$ & Laparoscopy $(\mathrm{N}=\mathbf{2 0})$ & Laparotomy $(n=69)$ & $P$ value \\
\hline \multicolumn{5}{|l|}{ Surgical procedures } \\
\hline Hysterectomy & $80(89.9 \%)$ & 17 (85.0\%) & $63(91.3 \%)$ & 0.414 \\
\hline Mono/Bilateral SO & $89(100.0 \%)$ & $20(100.0 \%)$ & $69(100.0 \%)$ & 1.000 \\
\hline Omentectomy & $84(94.4 \%)$ & $15(75.0 \%)$ & $69(100.0 \%)$ & 0.000 \\
\hline Peritoneal biopsy & $63(70.8 \%)$ & II (55.0\%) & $52(75.4 \%)$ & 0.097 \\
\hline Appendectomy & $8(9.0 \%)$ & $2(10.0 \%)$ & $6(8.7 \%)$ & 1.000 \\
\hline Lymphadenectomy & $66(74.2 \%)$ & $10(50.0 \%)$ & $56(81.2 \%)$ & 0.009 \\
\hline Pelvic only & $19(28.8 \%)$ & $4(40.0 \%)$ & $15(26.8 \%)$ & \\
\hline Aortic only & $3(4.5 \%)$ & 0 & $3(5.4 \%)$ & \\
\hline Pelvic \& Aortic & $44(66.7 \%)$ & $6(60.0 \%)$ & $38(67.9 \%)$ & \\
\hline \multicolumn{5}{|l|}{ Laparotomic conversion } \\
\hline No & & $8(40.0 \%)$ & & \\
\hline Yes (Immediate staging) & & $10(50.0 \%)$ & & \\
\hline Yes (Delayed staging) & & $2(10.0 \%)$ & & \\
\hline
\end{tabular}

Abbreviation: SO, salpingo-oophorectomy.

months), and 42.6 months and 36.5 months in the laparoscopy and open surgery groups, respectively. Overall, 9 (10.1\%) patients developed recurrence, and $4(4.5 \%)$ died of the disease; all were in the open surgery group. As shown in Figure 1A, the estimated 2-year PFS rates were $100.0 \%$ and $90.1 \%$ in the laparoscopy and open surgery groups, respectively ( $p=$ 0.081). There was also no significant difference in OS, with an estimated 5-year OS rate of $100.0 \%$ and $91.9 \%$ in the laparoscopy and open surgery groups, respectively $(p=0.230)$ (Figure 1B).

A

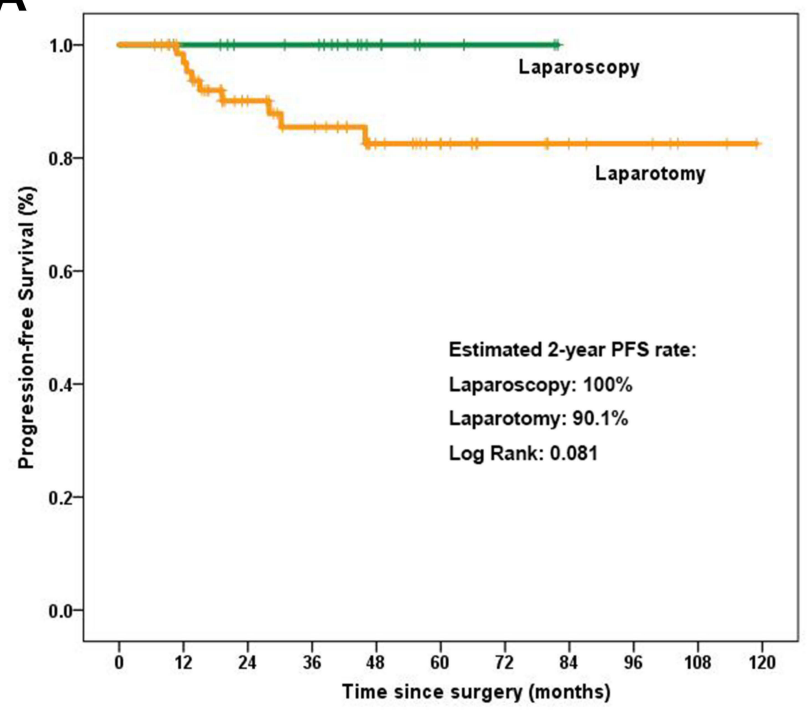

\section{Characteristics of the Recurrent Patients}

The clinical characteristics of the recurrent patients are listed in Table 3. In summary, 7/9 recurrent patients were diagnosed as FIGO stage IC, and 2 were FIGO stage IA. Eight patients received lymph node resection, and one patient did not. All patients underwent six or more cycles of chemotherapy, and the time to recurrence ranged from 10.7 to 45.9 months. Recurrent lesions were found in the pelvic and abdominal peritoneum in three patients, local pelvic recurrence developed in two patients, and retroperitoneal lymph node recurrence developed in two patients. One patient was diagnosed

B

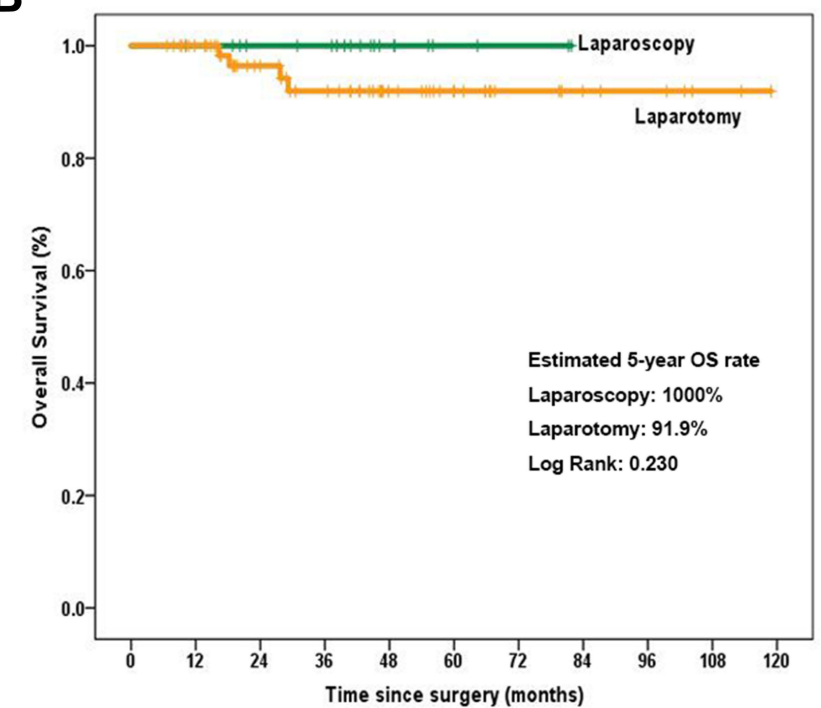

Figure I Kaplan-Meier plots for progression-free survival (A) and overall survival (B) between the laparoscopy and laparotomy groups. 
Table 3 Characteristics of Recurrent Patients

\begin{tabular}{|l|l|l|l|l|l|l|l|l|}
\hline No & Age & Stage & LNR & Chemo & Time to Recurrence (Mos) & Recurrent Sites & Treatment After Relapse & Status \\
\hline I & 57 & IC & Yes & DC*6 & 28.0 & Peritoneum & Surgery+Chemo \\
2 & 72 & IC & No & TC*7 & 45.9 & Pelvic & Surgery+Chemo \\
3 & 55 & IC & Yes & TC*6 & 13.6 & Liver parenchyma & Chemo \\
4 & 49 & IC & Yes & TC*6 & 30.2 & Lymph nodes & Surgery+Chemo \\
5 & 54 & IC & Yes & TC*6 & 19.2 & Ascites & Chemo \\
6 & 42 & IA & Yes & TC*6 & 15.0 & Peritoneum & Surgery+Chemo \\
7 & 48 & IC & Yes & TC*6 & 12.6 & Peritoneum & Chemo & AWD \\
8 & $5 I$ & IC & Yes & AC*7 & 12.0 & Lymph nodes & Chemo \\
9 & 46 & IA & Yes & TC*6 & 10.7 & Pelvic & Surgery+Chemo \\
\hline
\end{tabular}

Abbreviations: LNR, lymph node resection; DC, Docetaxel + Carboplatin; TC, Paclitaxel + Carboplatin; AC, Doxorubicin + Carboplatin; AWD, alive with disease; NED, no evidence of disease.

with recurrence according to the presence of ascites. These patients' treatments and status are listed in Table 3.

\section{Discussion}

Although MIS is widely applied in gynecological surgery, including to diagnose endometriosis, the impact on endometriosis-associated ovarian cancer, including OCCC, which is frequently misdiagnosed as early-stage ovarian endometrioid cyst, remains uncertain. The potential risks of MIS in ovarian cancer may include the following: First, laparoscopy may fail to evaluate tumor disease because of severe dense adhesions, and occult tumor lesions, such as on the posterior surface of the diaphragm that are expected to be identified by palpation during open surgery, may be neglected during MIS. ${ }^{18}$ Second, MIS may cause intraoperative cancer cell spillage, leading to peritoneal dissemination or port-site metastasis. ${ }^{19-21}$ Third, we still do not know if carbon dioxide $\left(\mathrm{CO}_{2}\right)$ pneumoperitoneum changes the tumor environment or the biological behavior of tumor cells; thus, promoting tumor spread or metastasis.

We found no survival differences, when we reviewed previous studies comparing the survival of patients with early-stage ovarian cancer between laparoscopic and open surgery groups; however, the study designs or the included patients differed in the studies. ${ }^{22-28}$ As shown in Table 4, most previous studies included patients with early EOC, and only one study focused on stage IC OCCC patients. ${ }^{25}$ In Chang et al's study, 88 patients with stage IC OCCC were included, and 76 (86.4\%) and 12 (13.6\%) underwent direct exploratory laparotomy staging and laparoscopy, respectively. ${ }^{25}$ All 12 patients who underwent laparoscopic staging were converted to open surgery after pathological confirmation, and no survival differences were identified between the groups. The authors' concluded that a laparoscopic diagnosis did not worsen patients' survival if direct open conversion was performed.

Differing from Chang et al's study, we included OCCC FIGO stage IA-IC patients and patients who received full laparoscopic staging as well as those who were converted to open surgery. Twenty of 89 patients underwent laparoscopic staging, and $12(60.0 \%)$ were converted to laparoscopic surgery directly or underwent delayed open surgery staging. Our results revealed no tumor recurrence in the laparoscopy group after a median follow-up of 42.6 months. These data may indicate that laparoscopic surgery has no impact on survival in stage I OCCC patients, regardless of whether the surgery was converted to open surgery.

Recently, a large study with a median follow-up of 61 months (range, 13-118 months) investigated the role of MIS for early-stage ovarian cancer patients. ${ }^{29}$ The authors concluded that grade 3 cancer was the most powerful prognostic factor for recurrence, whereas stage $>$ IC was correlated with shorter PFS, but without reaching statistical significance. Tumor grade, final FIGO stage, and the time of surgical staging (immediate versus delayed) maintained an independent favorable prognostic role for PFS by multivariate analysis. In our study, we did not perform univariate or multivariate analysis for tumor recurrence because of the low recurrence number, and because the follow-up period was too short.

Importantly, we noticed that although no statistical significance was found in most previous studies, a shorter PFS or OS rate was observed in patients receiving direct open surgery staging in many recent studies. ${ }^{25,26}$ These data may be explained by different baseline characteristics, including preoperative imaging to determine large tumor size, which may lead to a choice of direct 
Table 4 References Comparing Survival Between Open Surgery and MIS for Ovarian Cancer Patients with Early Stage

\begin{tabular}{|c|c|c|c|c|c|c|c|}
\hline Ref. ${ }^{22-28}$ & Patients & Group & $\begin{array}{l}\text { Patients } \\
\text { Number }\end{array}$ & $\begin{array}{l}\text { Follow-Up } \\
\text { (Months) }\end{array}$ & PFS Rate & OS Rate & $\begin{array}{l}\text { Survival } \\
\text { Difference }\end{array}$ \\
\hline \multirow[t]{2}{*}{ Ghezzi F. 2007} & \multirow[t]{2}{*}{ EOC } & $\begin{array}{l}\text { Open } \\
\text { surgery }\end{array}$ & 19 & $60(32-108)$ & $92.9 \%$ & $100 \%$ & \multirow[b]{2}{*}{ NA } \\
\hline & & Laparoscopy & 15 & $16(4-33)$ & $100 \%$ & $100 \%$ & \\
\hline \multirow[t]{2}{*}{ Park JY. 2008} & \multirow[t]{2}{*}{ EOC } & $\begin{array}{l}\text { Open } \\
\text { surgery }\end{array}$ & 33 & $23(I-44)$ & $100 \%$ & $100 \%$ & \multirow[b]{2}{*}{ NA } \\
\hline & & Laparoscopy & 19 & $17(2-40)$ & $100 \%$ & $100 \%$ & \\
\hline \multirow[t]{2}{*}{ Minig L, 2016} & \multirow[t]{2}{*}{ EOC } & $\begin{array}{l}\text { Open } \\
\text { surgery }\end{array}$ & 58 & $34.3(28.4-47.8)$ & $88 \%(5 \mathrm{I} / 58)$ & NA & \multirow[b]{2}{*}{ N.S } \\
\hline & & Laparoscopy & 50 & $25.9(11.2-38.5)$ & $88 \%(44 / 50)$ & NA & \\
\hline \multirow[t]{2}{*}{$\begin{array}{l}\text { Gallotta V, } \\
2016\end{array}$} & \multirow[t]{2}{*}{ EOC } & $\begin{array}{l}\text { Open } \\
\text { surgery }\end{array}$ & 120 & $38(24-48)$ & 4-year: $81 \%$ & 4-year: $91 \%$ & \multirow[b]{2}{*}{ N.S } \\
\hline & & Laparoscopy & 60 & $38(24-48)$ & 4 -year: $89 \%$ & 4-year: $92 \%$ & \\
\hline \multirow[t]{2}{*}{ Ditto A. 2017} & \multirow[t]{2}{*}{ EOC } & $\begin{array}{l}\text { Open } \\
\text { surgery }\end{array}$ & 50 & $52.6( \pm 81.8)$ & NA & NA & \multirow[b]{2}{*}{ N.S } \\
\hline & & Laparoscopy & 50 & $49.5( \pm 64)$ & NA & NA & \\
\hline \multirow[t]{2}{*}{$\begin{array}{l}\text { Chang HT. } \\
2020\end{array}$} & \multirow[t]{2}{*}{ occC } & $\begin{array}{l}\text { Open } \\
\text { surgery }\end{array}$ & 76 & NA & $\begin{array}{l}73.7 \%(56 / \\
76)\end{array}$ & $86.8 \%(66 / 76)$ & \multirow[b]{2}{*}{ N.S } \\
\hline & & Laparoscopy & 12 & NA & $\begin{array}{l}83.3 \%(10 / \\
12)\end{array}$ & $91.7 \%(11 / 12)$ & \\
\hline \multirow[t]{2}{*}{$\begin{array}{l}\text { Merlier } \\
\text { M. } 2020\end{array}$} & \multirow[t]{2}{*}{ EOC } & $\begin{array}{l}\text { Open } \\
\text { surgery }\end{array}$ & 107 & $42(24.0-66.0)$ & $\begin{array}{l}71 \%(76 / \\
107)\end{array}$ & $\begin{array}{l}84.1 \%(90 / \\
107)\end{array}$ & \multirow[b]{2}{*}{ N.S } \\
\hline & & Laparoscopy & 37 & $24(11.0-50.0)$ & $\begin{array}{l}94.6 \%(35 / \\
37)\end{array}$ & $97.3 \%(36 / 37)$ & \\
\hline
\end{tabular}

Abbreviations: MIS, minimally invasive surgery; EOC, epithelial ovarian cancer; OCCC, ovarian clear cell cancer; PFS, progression-free survival; OS, overall survival; NA, not acquired; N.S, none significance.

open surgery. However, no survival difference was identified between patients with tumor size $\leq 80 \mathrm{~mm}$ versus $>$ $80 \mathrm{~mm}$ in our study (data not shown). A well-designed, randomized controlled trial should be conducted to resolve this question.

\section{Conclusion}

This was a retrospective study comparing survival between early-stage OCCC patients who underwent laparoscopy versus open surgery. Our study concluded that survival was not compromised when primary laparoscopic surgery was performed in FIGO stage I OCCC patients.

\section{Funding}

This study was supported by the Zhongshan Development Program (XK-066) and the National Natural Science Foundation of China (81702548).

\section{Disclosure}

All authors report no conflicts of interest for this work.

\section{References}

1. Siegel RL, Miller KD, Jemal A. Cancer statistics, 2020. CA Cancer J Clin. 2020;70(1):7-30. doi:10.3322/caac.21590

2. Ceppi L, Grassi T, Galli F, et al. Early-stage clear cell ovarian cancer compared to high-grade histological subtypes: an outcome exploratory analysis in two oncology centers. Gynecol Oncol. 2021;160(1):64-70. 
3. Khalique S, Lord CJ, Banerjee S, et al. Translational genomics of ovarian clear cell carcinoma. Semin Cancer Biol. 2020;61:121-131. doi:10.1016/j.semcancer.2019.10.025

4. Iida Y, Okamoto A, Hollis RL, et al. Clear cell carcinoma of the ovary: a clinical and molecular perspective. Int J Gynecol Cancer. 2021;31(4):605-616. doi:10.1136/ijgc-2020-001656

5. Fagotti A, Perelli F, Pedone L, et al. Current recommendations for minimally invasive surgical staging in ovarian cancer. Curr Treat Options Oncol. 2016;17(1):3. doi:10.1007/s11864-015-0379-8

6. Fagotti A, Ferrandina G, Fanfani F, et al. Prospective validation of a laparoscopic predictive model for optimal cytoreduction in advanced ovarian carcinoma. Am J Obstet Gynecol. 2008;199 (6):642.e1-6. doi:10.1016/j.ajog.2008.06.052

7. Gueli AS, Petrillo M, Vizzielli G, et al. Minimally invasive versus standard laparotomic interval debulking surgery in ovarian neoplasm: a single-institution retrospective case-control study. Gynecol Oncol. 2016;143(3):516-520. doi:10.1016/j.ygyno.2016.10.017

8. Gueli AS, Bottoni C, Fanfani F, et al. Minimally invasive interval debulking surgery in ovarian neoplasm (MISSION trialNCT02324595): a feasibility study. Am J Obstet Gynecol. 2016;214 (4):503.e1-503.e6. doi:10.1016/j.ajog.2015.10.922

9. Fagotti A, Petrillo M, Costantini B, et al. Minimally invasive secondary cytoreduction plus HIPEC for recurrent ovarian cancer: a case series. Gynecol Oncol. 2014;132(2):303-306. doi:10.1016/j. ygyno.2013.12.028

10. Fagotti A, Costantini B, Gallotta V, et al. Minimally invasive secondary cytoreduction plus HIPEC versus open surgery plus HIPEC in isolated relapse from ovarian cancer: a retrospective cohort study on perioperative outcomes. J Minim Invasive Gynecol. 2015;22 (3):428-432. doi:10.1016/j.jmig.2014.11.008

11. Gallotta V, Ghezzi F, Vizza E, et al. Laparoscopic management of ovarian cancer patients with localized carcinomatosis and lymph node metastases: results of a retrospective multi-institutional series. J Minim Invasive Gynecol. 2016;23(4):590-596. doi:10.1016/j. jmig.2016.01.029

12. Gallotta V, Nero C, Lodoli C, et al. Laparoscopic splenectomy for secondary cytoreduction in ovarian cancer patients with localized spleen recurrence: feasibility and technique. J Minim Invasive Gynecol. 2016;23(3):425-428. doi:10.1016/j.jmig.2016.01.001

13. Gallotta V, Ghezzi F, Vizza E, et al. Laparoscopic staging of apparent early stage ovarian cancer: results of a large, retrospective, multi-institutional series. Gynecol Oncol. 2014;135(3):428-434. doi:10.1016/j.ygyno.2014.09.006

14. Ghezzi F, Malzoni M, Vizza E, et al. Laparoscopic staging of early ovarian cancer: results of a multi-institutional cohort study. Ann Surg Oncol. 2012;19(5):1589-1594. doi:10.1245/s10434-011-2138-9

15. Zhang Y, Fan S, Xiang Y, et al. Comparison of the prognosis and recurrence of apparent early-stage ovarian tumors treated with laparoscopy and laparotomy: a meta-analysis of clinical studies. BMC Cancer. 2015;15(1):597. doi:10.1186/s12885-015-1604-3

16. Melamed A, Keating NL, Clemmer JT, et al. Laparoscopic staging for apparent stage I epithelial ovarian cancer. Am J Obstet Gynecol. 2017;216(1):50.e1-50.e12. doi:10.1016/j.ajog.2016.08.030
17. Ramirez PT, Frumovitz M, Pareja R, et al. Minimally invasive versus abdominal radical hysterectomy for cervical cancer. $N$ Engl J Med. 2018;379(20):1895-1904. doi:10.1056/NEJMoa1806395

18. Wang P-H. The role of laparoscopy and the value of peritoneal carcinomatosis index in patients with intra-abdominal malignancies who are scheduled to laparotomy. Gynecol Minim Invasive Ther. 2019;8(2):51-52. doi:10.4103/GMIT.GMIT_93_18

19. Tantitamit T, Lee C-L. Is it the time for laparoscopic management of early-stage ovarian malignancies? Gynecol Minim Invasive Ther. 2018;7(3):93-103. doi:10.4103/GMIT.GMIT_59_18

20. Lee CL, Kay N. Inhibition of ovarian cancer growth and implantation by paclitaxel after laparoscopic surgery in a mouse model. Am $J$ Obstet Gynecol. 2006;195:1278-1281. doi:10.1016/j. ajog.2006.07.035

21. Lee CL, Kusunoki S, Huang CY, Wu KY, Lee PS, Huang KG. Surgical and survival outcomes of laparoscopic staging surgery for patients with stage I ovarian cancer. Taiwan J Obstet Gynecol. 2018;57:7-12. doi:10.1016/j.tjog.2017.12.002

22. Ghezzi F, Cromi A, Uccella S, et al. Laparoscopy versus laparotomy for the surgical management of apparent early stage ovarian cancer. Gynecol Oncol. 2007;105(2):409-413. doi:10.1016/j. ygyno.2006.12.025

23. Park J-Y, Kim D-Y, Suh D-S, et al. Comparison of laparoscopy and laparotomy in surgical staging of early-stage ovarian and fallopian tubal cancer. Ann Surg Oncol. 2008;15(7):2012-2019. doi:10.1245/ s10434-008-9893-2

24. Ditto A, Bogani G, Martinelli F, et al. Minimally invasive surgical staging for ovarian carcinoma: a propensity-matched comparison with traditional open surgery. J Minim Invasive Gynecol. 2017;24 (1):98-102. doi:10.1016/j.jmig.2016.09.018

25. Chang HT, Chiu ML, Wang TY, et al. Effect of chemotherapy, laparoscopy, and cytology on stage IC ovarian clear cell carcinoma: a Long-Term, Single-Center Study. Int J Environ Res Public Health. 2020;17(2):491.

26. Merlier M, Kerbage Y, Pierache A, et al. Impact on prognosis of the surgical route, laparoscopy or laparotomy, for the surgical staging of early stage ovarian cancer-a study from the FRANCOGYN Group. J Clin Med. 2020;9(11):11. doi:10.3390/jcm9113528

27. Minig L, Saadi J, Patrono MG, et al. Laparoscopic surgical staging in women with early stage epithelial ovarian cancer performed by recently certified gynecologic oncologists. Eur J Obstet Gynecol Reprod Biol. 2016;201:94-100. doi:10.1016/j.ejogrb.2016.03.029

28. Gallotta V, Petrillo M, Conte C, et al. Laparoscopic versus laparotomic surgical staging for early-stage ovarian cancer: a Case-Control Study. J Minim Invasive Gynecol. 2016;23:769-774. doi:10.1016/j. jmig.2016.03.006

29. Gallotta V, Jeong SY, Conte C, et al. Minimally invasive surgical staging for early stage ovarian cancer: a long-term follow up. Eur J Surg Oncol. 2021;47(7):1698-1704. doi:10.1016/j.ejso.2021.01.033
Cancer Management and Research is an international, peer-reviewed open access journal focusing on cancer research and the optimal use of preventative and integrated treatment interventions to achieve improved outcomes, enhanced survival and quality of life for the cancer patient.
The manuscript management system is completely online and includes a very quick and fair peer-review system, which is all easy to use. Visit http://www.dovepress.com/testimonials.php to read real quotes from published authors. 